\title{
Involvement of the Mediastinal Subpleural Pulmonary Parenchyma on Chest CT in COVID-19 patients: A Case Series
}

\author{
Luigi Urciuoli $^{1}$, Elvira Guerriero ${ }^{2 *}$, Lanfranco Musto ${ }^{1}$ \\ 1. Department of Radiology, G. Criscuoli Hospital, Sant'Angelo dei Lombardi, ASL Avellino, Avellino, Italy \\ 2. Department of Advanced Biomedical Sciences, University Federico II, Naples, Italy \\ * Correspondence: Elvira Guerriero: Department of Advanced Biomedical Sciences, University "Federico II", Via S Pansini, 5, 80131, \\ Naples, Italy \\ (글elvira.guerriero91@gmail.com)
}

Radiology Case. 2020 Nov; 14(11):1-15 :: $\quad$ DOI: $10.3941 /$ jrcr.v14i11.3974

\begin{abstract}
Coronavirus disease 2019 (COVID-19) is an infectious disease caused by the severe acute respiratory syndrome coronavirus 2 (SARS-CoV-2). First identified in December 2019 in Wuhan, China, it has since become a global pandemic. Although the reference standard for SARS-CoV-2 diagnosis is real-time reverse transcription polymerase chain reaction (RT-PCR), computed tomography (CT) is recommended for both initial evaluation and follow-up. The CT findings in COVID-19 are varied, but typical groundglass opacities are usually reported to occupy a peripheral costal subpleural distribution. Here we report eight confirmed COVID-19 cases who underwent clinical evaluation, laboratory testing, and unenhanced chest CT. In all patients, chest CT showed the presence of ground-glass opacities in the mediastinal subpleural parenchyma. While these cases also showed the typical CT features of COVID-19, involvement of the mediastinal subpleural parenchyma should not lower the index of suspicion for COVID-19.
\end{abstract}

\section{CASE SERIES}

\section{CASE SERIES}

\section{INTRODUCTION}

COVID-19 (coronavirus disease 2019), caused by severe acute respiratory syndrome coronavirus 2 (SARS-CoV-2) [1], originated in China in December 2019 [2]. Since the WHO declared a global health emergency on January 30, 2020 and as of October 27, 2020, there have been an estimated $43,341,451$ cases and 1,157,509 deaths in over 200 countries [3]. In the Chinese population, 55-60\% COVID-19 patients were male, with a median age of between 47 and 59 years [4].
While understood to be diverse, it is now appreciated that the CT findings in COVID-19 patients typically show groundglass opacification (GGO) with occasional consolidation in a peripheral, subcostal distribution. Here we present a series of eight patients presenting with mild COVID-19 showing chest CT features of GGOs with a mediastinal distribution in additional to more typically described features. This series reinforces that involvement of the mediastinal subpleural parenchyma should not lower the index of suspicion for COVID-19. 


\section{CASE SERIES}

In all eight cases, real-time reverse transcription polymerase chain reaction (RT-PCR) performed on the patients' nasal swab samples was positive for SARS-CoV-2.

The patients were placed in isolation and received symptomatic and antibiotic treatment with no need of oxygen therapy; all patients had been discharged when they recovered uneventfully with 2 consecutive respiratory samples tested negative for SARS-CoV-2.

\section{CASE 1}

A 45-year-old woman, previously in good health, presented to the emergency department (ED) with myalgia, asthenia and she also had a body temperature of $37,4{ }^{\circ} \mathrm{C}$ for three days. Oxygen saturation ( $\mathrm{sO} 2)$ was $98 \%$ and all laboratory results were normal. An unenhanced chest computed tomography (CT) showed multiple, rounded ground-glass opacities (GGOs), especially in the right lower lobe (Fig. 1) and in the paratracheal subpleural parenchyma (Fig. 2)

\section{CASE 2}

A 49-year-old man was admitted to hospital with a fever $\left(38^{\circ} \mathrm{C}\right)$ and slight cough. Laboratory tests revealed: a slightly decreased white blood cell count (WBC) 3.8 x 109/L (4$11 \times 109 / \mathrm{L}$ ) and a normal absolute lymphocyte count (ALC) 1.3 x 109/L (0,9-2,9x109/L). Procalcitonin-PCT $0.12 \mathrm{ng} / \mathrm{mL}(<0,5$ $\mathrm{ng} / \mathrm{mL})$, C-reactive protein-CRP $5.2 \mathrm{mg} / \mathrm{L}(<10 \mathrm{mg} / \mathrm{L})$, and sO2 $(97 \%)$ were within normal limits. A chest CT showed multifocal, diffuse GGOs in the left lower lobe (Fig. 3). There were also patchy pure GGOs in the mediastinal subpleural zones in the right posterior costo-mediastinal and para-aortic areas (Fig. 4).

\section{CASE 3}

A 66-year-old man with a 20-pack-year smoking history was admitted to hospital with a seven-day history of fever $\left(38^{\circ} \mathrm{C}\right)$, chest tightness, and muscle pain. Coarse breath sounds at the bases of both lungs were heard on auscultation. $\mathrm{sO} 2$ was $96 \%$, and laboratory tests showed a normal WBC $9.9 \times 109 / \mathrm{L}$ (4-11x109/L), ALC 0.9 x 109/L (0,9-2,9x109/L), CRP 7 mg/L (<10 mg/L), and PCT $0.3 \mathrm{ng} / \mathrm{mL}(<0,5 \mathrm{ng} / \mathrm{mL})$. Chest CT showed bilateral peripheral patchy GGOs superimposed on septal thickening (a "crazy paving" pattern) with partial consolidation in the right lower lobe (Fig. 5) and in the mediastinal subpleural zones in the left paracardiac and right posterior costo-mediastinal areas. A right pleural effusion was also noted (Fig. 6).

\section{CASE 4}

A 61-year-old previously healthy man presented to the ED with a five-day history of sore throat and fever $\left(37.8^{\circ} \mathrm{C}\right)$. sO2 was $98 \%$, and laboratory tests showed: a normal WBC $5.2 \times 109 / \mathrm{L}(4-11 \times 109 / \mathrm{L})$, ALC 1.4 x 109/L (0,9-2,9x109/L), CRP $5.1 \mathrm{mg} / \mathrm{L}(<10 \mathrm{mg} / \mathrm{L})$, and PCT $0.5 \mathrm{ng} / \mathrm{mL}(<0,5$ $\mathrm{ng} / \mathrm{mL})$. A chest $\mathrm{CT}$ showed multiple rounded GGOs in the right upper lobe and a diffuse GGO with contextual septal thickening (crazy paving pattern) in the periphery of the right lower lobe (Fig. 7). Patchy GGOs were also noted with a mediastinal subpleural distribution around the descending aorta (Fig. 8).

\section{CASE 5}

A 58-year-old man presented with a five-day history of fever and recent onset dyspnea. The patient had no other comorbidities. Physical examination revealed tachypnea and a temperature of $39^{\circ} \mathrm{C}$. Coarse breath sounds were heard on auscultation at admission. sO2 was $98 \%$, and laboratory tests revealed: neutrophilia 9 x 109/L (1,7-7 x 109/L), lymphopenia 0.6 x 109/L (0.9-2,9 x109/L), an elevated CRP $111 \mathrm{mg} / \mathrm{L}(<10$ $\mathrm{mg} / \mathrm{L}$ ), and elevated lactic acid dehydrogenase LDH $392 \mathrm{U} / \mathrm{L}$ (105-333 U/L). Chest CT showed bilateral bronchovascular and peripheral GGOs and consolidation of the posterior segments of the lower lobes (Fig. 9). Rounded mediastinal subpleural GGOs were also detected bilaterally in the paratracheal area (Fig. 10).

\section{CASE 6}

A 75-year-old man with a previous heart transplant presented to the ED with recent onset low-grade fever, asthenia and diarrhea. Laboratory tests showed: a slightly decreased WBC $3.9 \times 109 / \mathrm{L}(4-11 \times 109 / \mathrm{L})$ and ALC $0.8 \times$ 109/L (0,9-2,9 x 109/L) but normal CRP 3.3 mg/L (<10 mg/L) and PCT $0.5 \mathrm{ng} / \mathrm{mL}(<0,5 \mathrm{ng} / \mathrm{mL})$. sO2 was $98.7 \%$, and Chest CT revealed multiple nodules in the right lung with faint surrounding ground glass attenuation (halo sign; Fig. 11). In the right lung, focal rounded GGOs were also seen in the mediastinal subpleural areas (posterior costo-mediastinal, para-aortic, and paratracheal; Fig. 12).

\section{CASE 7}

A 60-year-old woman was admitted to hospital with a four-day history of dry cough, fever, and myalgia. She had a ten-year history of hypertension. At presentation, her temperature was $37.7^{\circ} \mathrm{C}$. sO2 was $97 \%$, and laboratory tests showed: a normal WBC 4.3 x 109/L (4-11x109/L), ALC 1.3 x 109/L (0,9-2,9 x 109/L), CRP $1.2 \mathrm{mg} / \mathrm{L}(<10 \mathrm{mg} / \mathrm{L})$ and PCT $0.4 \mathrm{ng} / \mathrm{mL}(<0,5 \mathrm{ng} / \mathrm{mL})$. Chest CT demonstrated peripheral and bilateral patchy GGOs with superimposed septal thickening (crazy paving pattern) in the upper lobes (Fig. 13). Other similar opacities were detected in the left perihilar area and in the right costo-mediastinal space (Fig. 14). Some mediastinal lymph nodes were enlarged (Fig. 13).

\section{CASE 8}

An 86-year-old man was admitted to hospital with recent onset fever, dry cough, and asthenia. He had a history of hypertension and diabetes. At presentation, his temperature was $38^{\circ} \mathrm{C}$, sO2 was $95 \%$, and laboratory tests showed: a normal WBC 4 x 109/L (4-11x109/L), ALC 1.2 x 109/L (0,9$2,9 \times 109 / \mathrm{L})$, CRP $2 \mathrm{mg} / \mathrm{L}(<10 \mathrm{mg} / \mathrm{L})$ and PCT $0,5 \mathrm{ng} / \mathrm{mL}$ $(0,5 \mathrm{ng} / \mathrm{mL})$. Chest CT showed patchy GGOs in the apical segment of the right lower lobe (Fig. 15) and focal GGOs with 
a mediastinal subpleural distribution in the right periaortic area (Fig. 16).

\section{DISCUSSION}

\section{Etiology \& Demographics:}

COVID-19 (coronavirus disease 2019) is an infectious disease caused by severe acute respiratory syndrome coronavirus 2 (SARS-CoV-2) [1], which is thought to have originated from a fish and wild animal market in Wuhan, the capital of China's Hubei province, in December 2019 [2]. The WHO declared a global health emergency on January 30, 2020. As of October 27, 2020, there have been an estimated 43,341,451 cases and 1,157,509 deaths in over 200 countries [3]. In the Chinese population, 55-60\% COVID-19 patients were male, with a median age of between 47 and 59 years [4].

\section{Clinical \& Imaging findings:}

COVID-19 typically presents with systemic and/or respiratory manifestations, especially fever (87.9\%), fatigue (38.1\%), and dry cough (67.7\%). Some patients have sputum production $(33.4 \%)$ and dyspnea $(18.6 \%)$, and a few patients have symptoms such as headache $(13.6 \%)$, sore throat (13.9\%), muscle pain (14.8\%), nasal congestion (4.8\%), nausea or vomiting $(5 \%)$, and diarrhea $(3.7 \%)$. In severe cases, acute respiratory distress syndrome, septic shock, difficult to correct metabolic acidosis, and coagulation dysfunction develop rapidly $[5,6]$.

The reference standard for the diagnosis of the infection is RT-PCR of viral nucleic acids [6] extracted from clinical specimens. Although RT-PCR of nasal swabs has been widely used to confirm the clinical diagnosis, Wang et al. [7] reported that nasal swab sampling has a lower sensitivity (63\%) than other sample types such as bronchoalveolar lavage fluid (93\%) and sputum (72\%) but a higher sensitivity than fibrobronchoscopic brush biopsy (46\%), pharyngeal swabs $(32 \%)$, feces $(29 \%)$, and blood $(1 \%)$.

Radiological examination plays an important role in the early detection and management of the infection. Although less sensitive than chest CT, chest radiography is typically the first-line imaging modality for patients with suspected COVID-19, but chest radiographs can be normal in early or mild disease. Radiological findings are most extensive about 9-12 days after symptom onset. The most frequent findings are airspace opacities described as consolidation or, less commonly, GGOs in a bilateral and peripheral distribution, with a lower lobe predominance. Pleural effusion is rare $[8,9]$.

Chest CT is strongly recommended in suspected cases for both initial evaluation and follow-up [10,11]. A wide variety of CT findings have been reported in COVID-19 patients in different studies $[12,13]$. However, the main CT features of COVID-19 pneumonia are multifocal bilateral GGOs, typically with a peripheral and subpleural distribution. Pure GGO lesions can be an early sign of the infection. Isolated GGOs or a combination of GGOs and consolidative opacities are some of the most common CT findings, while pure consolidation is relatively less common or absent. GGOs are hazy increases in attenuation with preservation of the bronchial and vascular margins that appear in a variety of interstitial and alveolar pathologies, while consolidation describes an area of opacification obscuring the margins of vessels and airway walls.

In the majority of COVID-19 patients, multiple lobes are involved, especially the lower lobes, while the right middle lobe is less frequently involved. GGOs associated with superimposed intralobular reticulations, resulting in a "crazy paving pattern", have also been reported. The crazy paving pattern can be seen as thickened interlobular septa and intralobular lines superimposed on a GGO background, resembling irregular paving stones. Linear consolidations and other signs suggesting organizing pneumonia such as the reversed halo sign (GCO areas surrounded by a complete or almost complete ring of consolidation) have also been observed, mostly in patients several days after disease onset.

Vascular enlargement (dilatation of pulmonary vessels around and within lesions) and multifocal solid irregular nodules or nodules with a visible halo sign (GGO surrounding a pulmonary nodule or mass) have also been reported. Septal thickening, airway changes (traction bronchiectasis and bronchial wall thickening), and subpleural curvilinear lines are some of the less common findings, mainly in the later stages of the disease. Tree-in-bud opacities (multiple areas of centrilobular nodules with a linear branching pattern), pleural and pericardial effusions, lymphadenopathy, cavitation, and pneumothorax have rarely been reported [14-16].

Patients with COVID-19 pneumonia present with variable lung involvement ranging from mild involvement affecting $<10 \%$ of the lung parenchyma to severe disease with a "white lung" appearance on CT. Follow-up CT in the intermediate stages of the disease tends to show an increase in the number and size of GGOs, progressive transformation of GGOs into multifocal consolidation, septal thickening, and development of a crazy paving pattern [17-19]. In patients with clinical worsening not explained by an extension of lung opacities on CT, pulmonary embolism should be suspected and a contrastenhanced CT should be performed [20].

Our eight confirmed COVID-19 cases all presented with mild symptoms such as asthenia, myalgia, cough, and fever. Chest CT showed the presence of focal rounded pure GGOs or GGOs with smooth septal thickening located in both the costal and mediastinal subpleural peripheral parenchyma. The parietal pleura, which lines the inner chest wall, can be divided into costal and mediastinal pleura according to site. In the same way, we divided the involved peripheral subpleural parenchyma into costal and mediastinal subpleural parenchyma.

Costal subpleural involvement was mainly in the lower lobes, whereas mediastinal subpleural involvement was usually observed in the upper/middle regions and was easily detected by multiplanar reformation (MPR) (Fig. 2 and Fig. 12).

The mediastinal subpleural localization included the paratracheal area (Figs 2, 10, and 12), the posterior costomediastinal area (Figs 4, 6, 12, and 14), the para-aortic area (Figs 4, 8, 12, and 16), the paracardiac area (Fig. 6), and the 
perihilar space (Fig. 14). To our best knowledge, while peripheral costal localization of GGOs (bilaterally in the lower lobes) is well described, the involvement of the peripheral mediastinal subpleural parenchyma (upper/middle zone, often unilaterally), is still poorly described. Our case series clearly shows that the mediastinal distribution is entirely consistent with COVID-19.

We also observed some of the typical CT imaging features described above. Pure GGOs with a peripheral costal subpleural distribution were present in four patients (Figs 1, 3, and 7). Combined GGOs and consolidative opacities were observed in two patients (Figs 5 and 9), while three patients presented with a crazy paving pattern (Figs 5, 7, and 13). The halo sign (Fig. 11), enlargement of mediastinal lymph nodes (Fig. 13), and pleural effusion (Fig. 6) were each detected in one case. No cavities, tree-in-bud opacities, or nodules were noted in accordance to their low prevalence reported in the literature.

\section{Treatment \& Prognosis:}

In Italian patients who died from COVID-19, the most important comorbidities were hypertension, diabetes, ischemic heart disease, atrial fibrillation, and chronic renal failure. The case fatality rate in Italy has been reported to be $15.3 \%$ in 70 79-year-old patients, $23.2 \%$ in 80-89-year-old patients, and $25.65 \%$, in 90 -year-old patients. There are currently no specific treatments or vaccines for COVID-19. Therefore, empirical treatment with antibiotics, antivirals, corticosteroids, and supportive measures have been used with some success (Table 1) [21].

\section{Differential Diagnosis:}

The high-resolution CT (HRCT) features of COVID-19 pneumonia are non-specific and may be encountered in other lung infections caused by Streptococcus, atypical organisms (Chlamydia, Mycoplasma), influenza virus, cytomegalovirus (CMV), and other coronaviruses such as SARS (severe acute respiratory syndrome) and MERS (middle-east respiratory syndrome). Of the differential diagnoses, the most challenging is pneumonia due to other viral causes.

\section{Influenza A (H1N1)}

In influenza-related pneumonia, the chest radiograph is often normal. Initial chest radiographs can show central or peripheral pulmonary GGOs and consolidation. Multiple and bilateral peripheral opacities are associated with an adverse prognosis. However, a normal radiograph cannot exclude a poor outcome. Chest CT shows a combination of small patchy ground glass and consolidative opacities with a subpleural and/or peri-bronchial distribution.

\section{SARS}

In SARS, the initial chest radiograph may be normal. Findings are non-specific, the most common being focal opacities followed by multifocal opacities in the middle and lower zones and GGOs (unilateral or bilateral). Chest CT shows subpleural (unilateral or bilateral) GGOs associated with consolidation, especially in the lower lobes, and interlobular and intralobular septal thickening.

\section{MERS}

In MERS, chest radiographs can show peripheral GGOs and consolidation. Pneumothoraces, pleural effusions, and progressive involvement of all lung zones are associated with a higher mortality. The common CT findings include diffuse bilateral subpleural GGOs associated with interlobular and intralobular septal thickening and pleural effusions (Table 2).

Therefore, the CT features of these viral infections overlap, so it is mainly the current epidemic context that suggests COVID-19 as the cause of GGOs in patients with fever and respiratory symptoms [22-24].

\section{CONCLUSION}

Our eight patients presenting with mild COVID-19 highlight the heterogeneous chest CT features seen in COVID19. In addition to the more "typical" features of peripheral subcostal GGOs and patchy consolidation described thus far in the pandemic, this series reinforces that radiologists must be aware of the involvement of the mediastinal subpleural parenchyma in COVID-19. Therefore, GGOs or other features seen with this distribution should not lower the index of suspicion for COVID-19.

\section{TEACHING POINT}

In the early stages of Coronavirus Disease-19 pneumonia, looking for Ground Glass Opacities in all subpleural areas, both costal and mediastinal, is mandatory. The involvement of mediastinal subpleural zones can be easily detected by thinsection multiplanar reformation.

\section{REFERENCES}

1. Zhu N, Zhang D, Wang W, et al. A novel coronavirus from patients with pneumonia in China, 2019. N Engl J Med. 2020 Feb 20;382(8):727-733. PMID:31978945.

2. Lu H, Stratton CW, Tang YW. Outbreak of pneumonia of unknown etiology in Wuhan, China: The mystery and the miracle. J Med Virol. 2020 Apr;92(4):401-402. PMID: 31950516

3. Coronavirus disease (COVID-19) Pandemic. Geneva: World Health Organization, October 27, 2020 (https://www.who.int/emergencies/diseases/novelcoronavirus-2019).

4. Guan WJ, Ni ZY, Hu Y et al., China Medical Treatment Expert Group for Covid-19. Clinical Characteristics of Coronavirus Disease 2019 in China. N Engl J Med. 2020 Apr 30;382(18):1708-1720. PMID: 32109013.

5. Huang C, Wang Y, Li X et al Clinical features of patients infected with 2019 novel coronavirus in Wuhan, China. Lancet. 2020 Feb 15;395(10223):497-506. PMID: 31986264. 
6. Report of the WHO-China Joint Mission on Coronavirus Disease 2019 (COVID-19), February 16-24, 2020.

7. Wang W, Xu Y, Gao R et al. Detection of SARS-CoV-2 in Different Types of Clinical Specimens. JAMA. 2020 Mar 11. PMID: 32159775.

8. Wong HYF, Lam HYS, Fong AH et al. Frequency and Distribution of Chest Radiographic Findings in COVID-19 Positive Patients. Radiology. 2019 Mar 27:201160. PMID: 32216717.

9. Jacobi A, Chung M, Bernheim A, Eber C. Portable chest Xray in coronavirus disease-19 (COVID-19): A pictorial review. Clin Imaging. 2020 Apr 8;64:35-42. PMID: 32302927.

10. Caruso D, Zerunian M, Polici M et al. Chest CT Features of COVID-19 in Rome, Italy. Radiology. 2020 Apr 3:201237. PMID: 32243238.

11. Lee EYP, Ng MY, Khong PL. COVID-19 pneumonia: what has CT taught us? Lancet Infect Dis. 2020 Apr;20(4):384-385. PMID: 32105641.

12. Kanne JP, Little BP, Chung JH, Elicker BM, Ketai LH. Essentials for Radiologists on COVID-19: An UpdateRadiology Scientific Expert Panel. Radiology. 2020 Feb 27:200527. PMID: 32105562.

13. Ng MY, Lee EY, Yang J, et al. Imaging Profile of the COVID-19 Infection: Radiologic Findings and Literature Review. Radiol Cardiothorac Imaging. 2020 Feb 13;2(1):e200034.

14. Zhou S, Wang $\mathrm{Y}$, Zhu $\mathrm{T}$, Xia L. CT Features of Coronavirus Disease 2019 (COVID-19) Pneumonia in 62 Patients in Wuhan, China. AJR Am J Roentgenol. 2020 Mar 5:1-8. PMID: 32134681.

15. Ye Z, Zhang Y, Wang Y, Huang Z, Song B. Chest CT manifestations of new coronavirus disease 2019 (COVID-19): a pictorial review. Eur Radiol. 2020 Mar 19. PMID: 32193638 .

16. Hani C, Trieu NH, Saab I, Dangeard S, Bennani S, Chassagnon G, Revel MP. COVID-19 pneumonia: a review of typical CT findings and differential diagnosis. Diagnostic and Interventional Imaging. 2020.

17. Pan $\mathrm{Y}$, Guan $\mathrm{H}$, Zhou $\mathrm{S}$, et al. Initial $\mathrm{CT}$ findings and temporal changes in patients with the novel coronavirus pneumonia (2019-nCoV): a study of 63 patients in Wuhan, China. Eur Radiol. 2020 Feb 13. PMID: 32055945.

18. Salehi S, Abedi A, Balakrishnan S, Gholamrezanezhad A. Coronavirus Disease 2019 (COVID-19): A Systematic Review of Imaging Findings in 919 Patients. AJR Am J Roentgenol. 2020 Mar 14:1-7. PMID: 32174129.

19. Shi H, Han X, Jiang N. et al. Radiological findings from 81 patients with COVID-19 pneumonia in Wuhan, China: a descriptive study. Lancet Infect Dis. 2020 Apr;20(4):425-434. PMID: 32105637.

20. Tang N, Li D, Wang X, Sun Z. Abnormal coagulation parameters are associated with poor prognosis in patients with novel coronavirus pneumonia. J Thromb Haemost. 2020 Apr;18(4):844-847. PMID: 32073213.

21. COVID-19 SURVEILLANCE GROUP, et al. Characteristics of COVID-19 patients dying in Italy: report based on available data on March 20th, 2020. Rome, Italy: Instituto Superiore Di Sanita; 2020.

22. Bai HX, Hsieh B, Xiong $\mathrm{Z}$ et al. Performance of radiologists in differentiating COVID-19 from viral pneumonia on chest CT. Radiology. 2020 Mar 10:200823. PMID: 32155105.

23. Kay F, Abbara S. The many faces of COVID-19: spectrum of imaging manifestations. Radiology Cardiothoracic Imaging. 2020.

24. Zu ZY, Jiang MD, Xu PP, Chen W, Ni QQ, Lu GM, Zhang LJ. Coronavirus Disease 2019 (COVID-19): A Perspective from China. Radiology. 2020 Feb 21:200490. PMID: 32083985. 


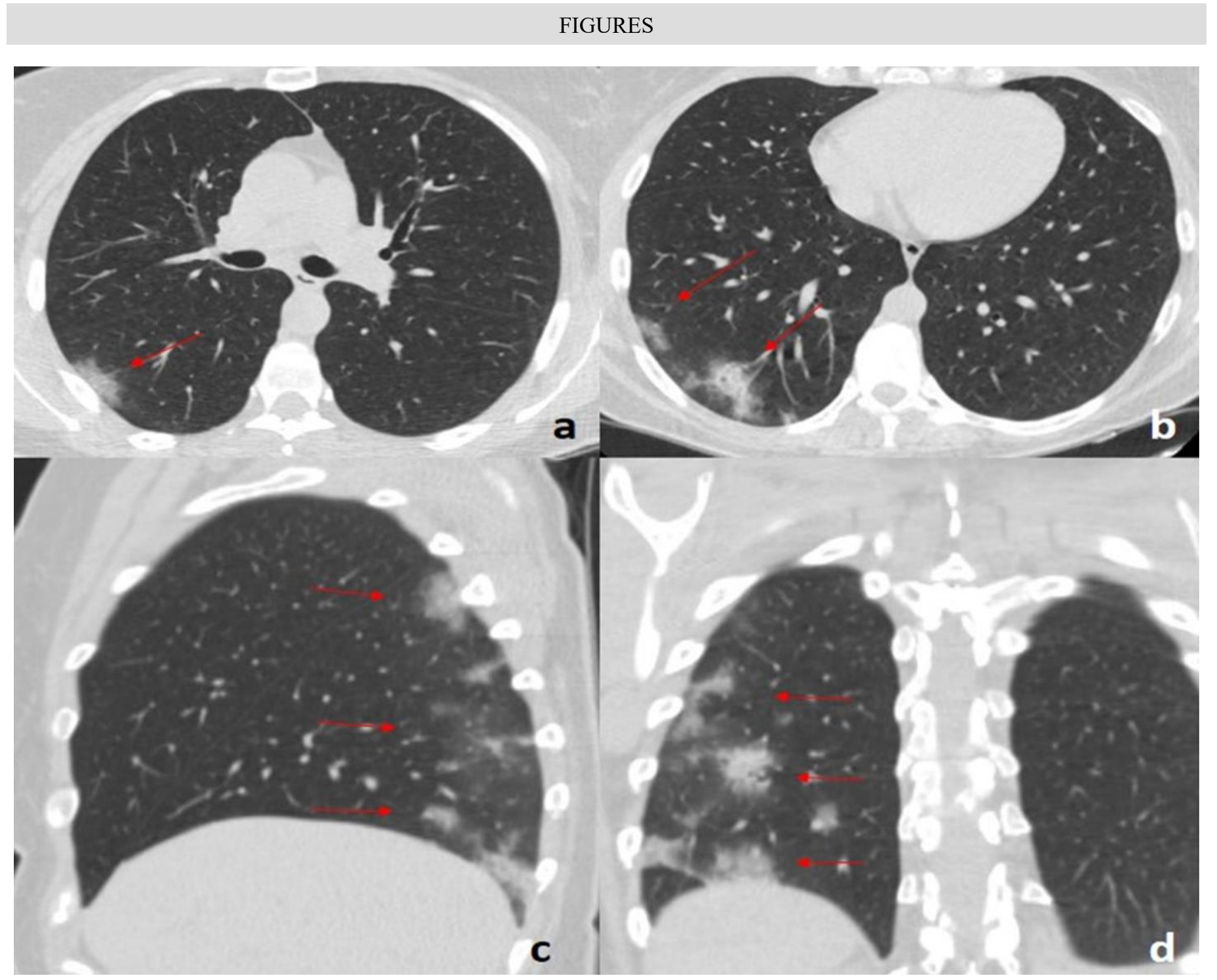

Figure 1: 45-year-old woman with COVID-19 pneumonia.

FINDINGS: Axial (a, b), sagittal (c), and coronal (d) unenhanced chest CTs demonstrate multiple, subpleural GGOs with a rounded morphology (arrows) in the right lower lobe.

TECHNIQUE: GE 16-slices CT scanner, 80-300 mAs, $120 \mathrm{kV}, 1.25 \mathrm{~mm}$ slice thickness. 


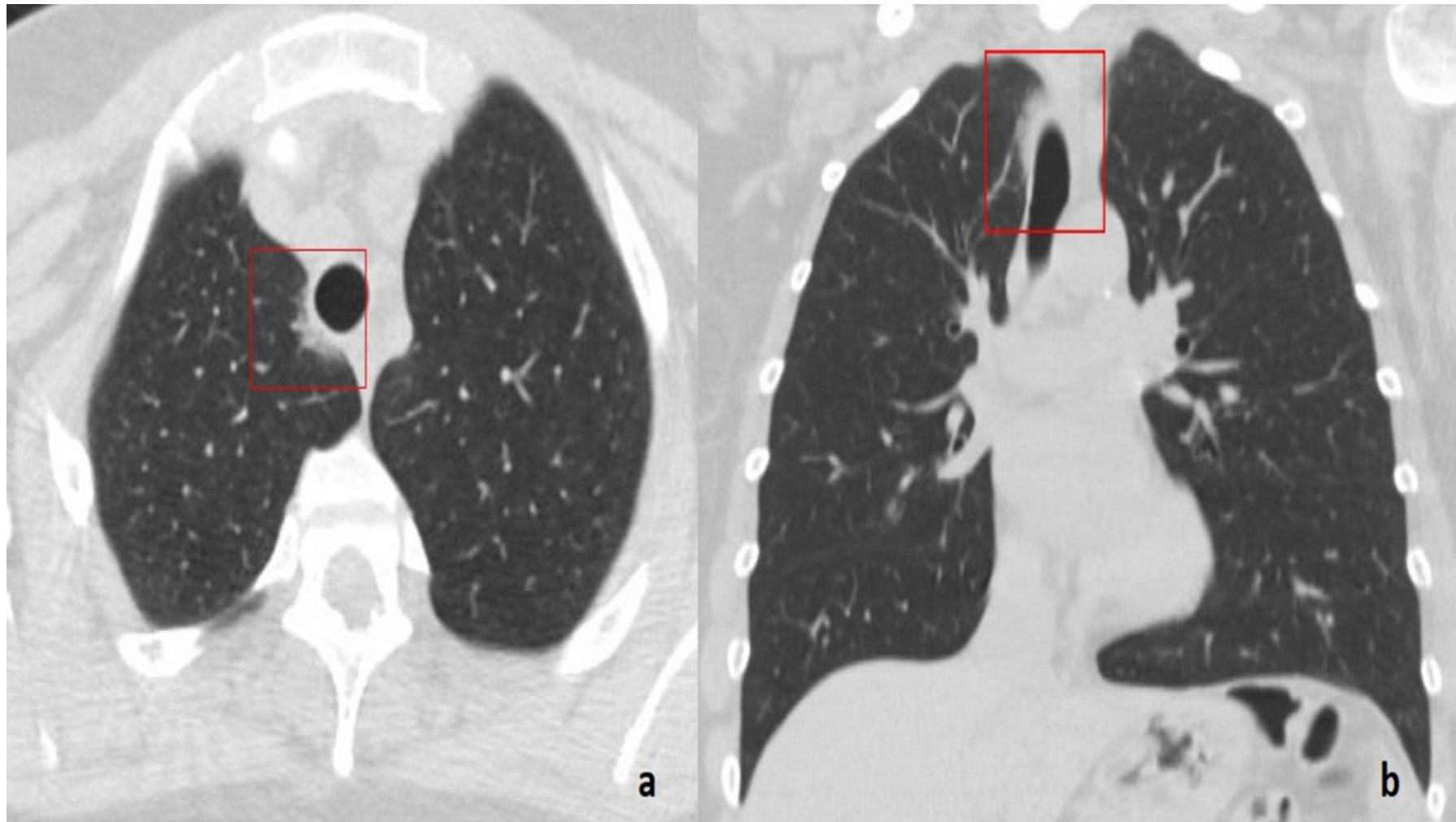

Figure 2: 45-year-old woman with COVID-19 pneumonia.

FINDINGS: Axial (a) and coronal (b) unenhanced chest CTs show a band-like GGO in the right paratracheal parenchyma (box).

TECHNIQUE: GE 16-slices CT scanner, 80-300 mAs, $120 \mathrm{kV}, 1.25 \mathrm{~mm}$ slice thickness.

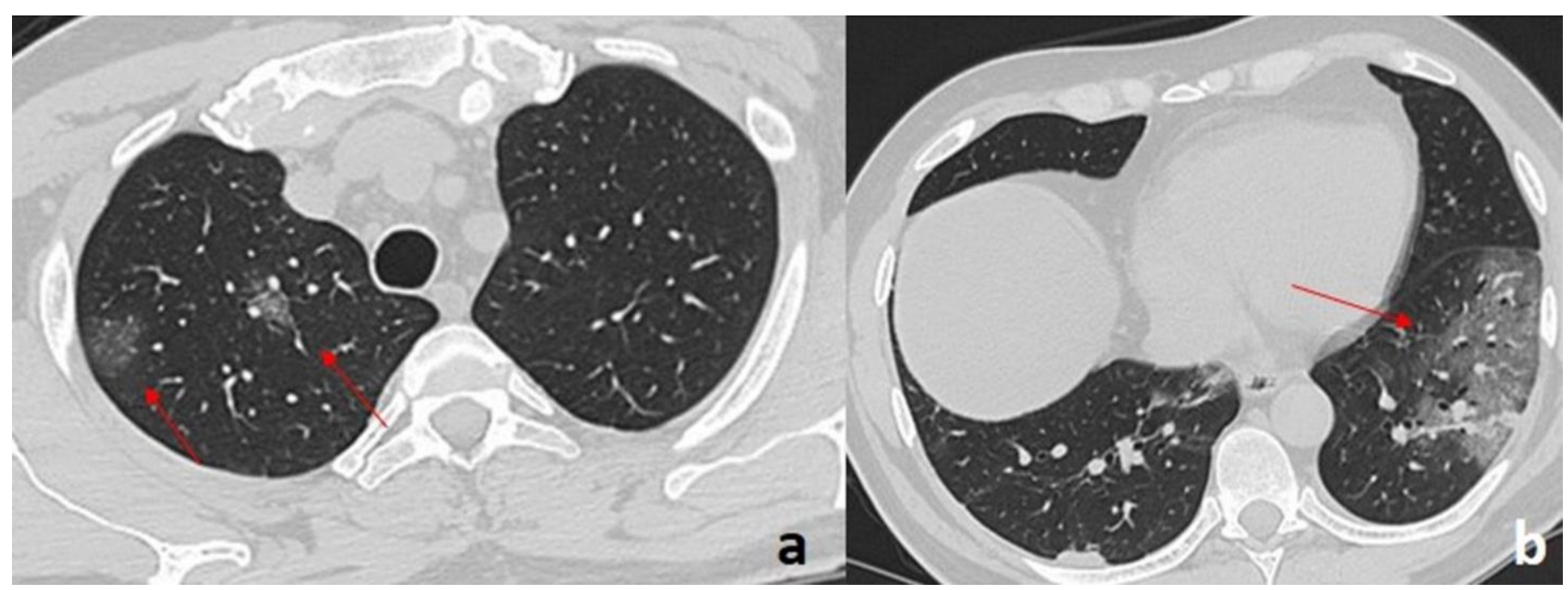

Figure 3: 49-year-old man with COVID-19 pneumonia.

FINDINGS: Axial unenhanced chest CT demonstrates multiple GGOs (arrows) with a rounded morphology in the upper right lobe (arrows in a), and a diffuse area of GGO with a striking peripheral distribution in the left lower lobe (arrow in b).

TECHNIQUE: GE 16-slices CT scanner, 80-300 mAs, $120 \mathrm{kV}, 1.25 \mathrm{~mm}$ slice thickness. 


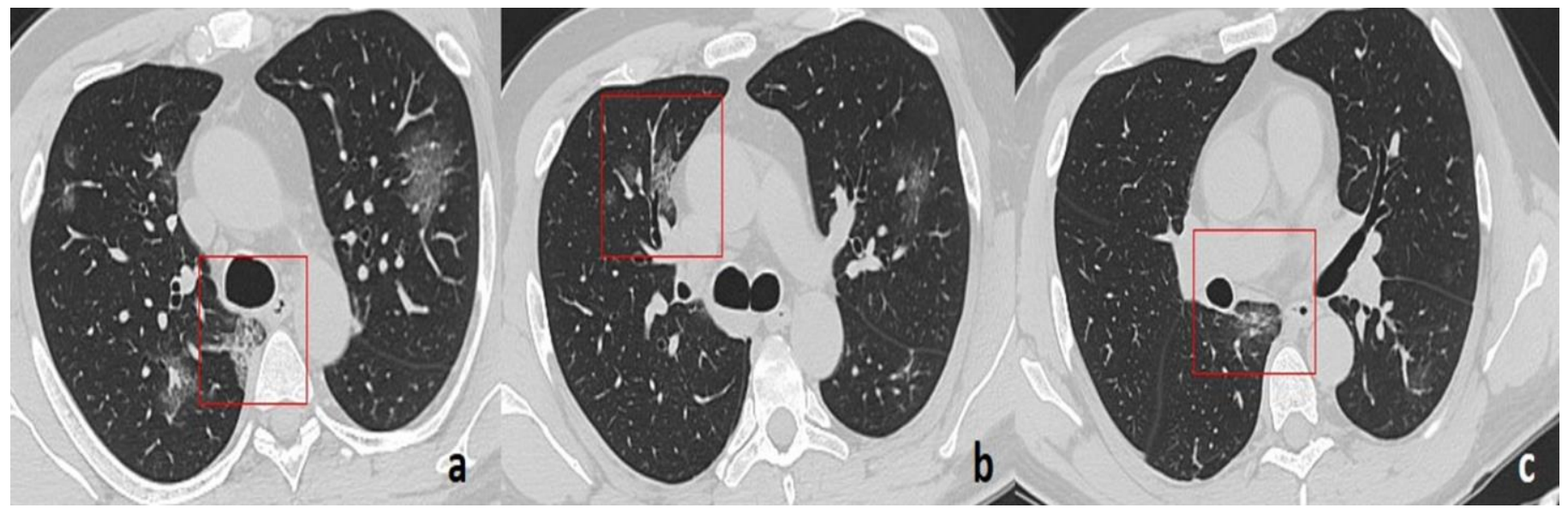

Figure 4: 49-year-old man with COVID-19 pneumonia.

FINDINGS: Axial unenhanced chest CT demonstrates multiple GGOs with a rounded morphology (boxes) in the right lung involving the mediastinal subpleural parenchyma (posterior costo-mediastinal (a, c) and para-aortic (b)).

TECHNIQUE: GE 16-slices CT scanner, 80-300 mAs, $120 \mathrm{kV}, 1.25 \mathrm{~mm}$ slice thickness.
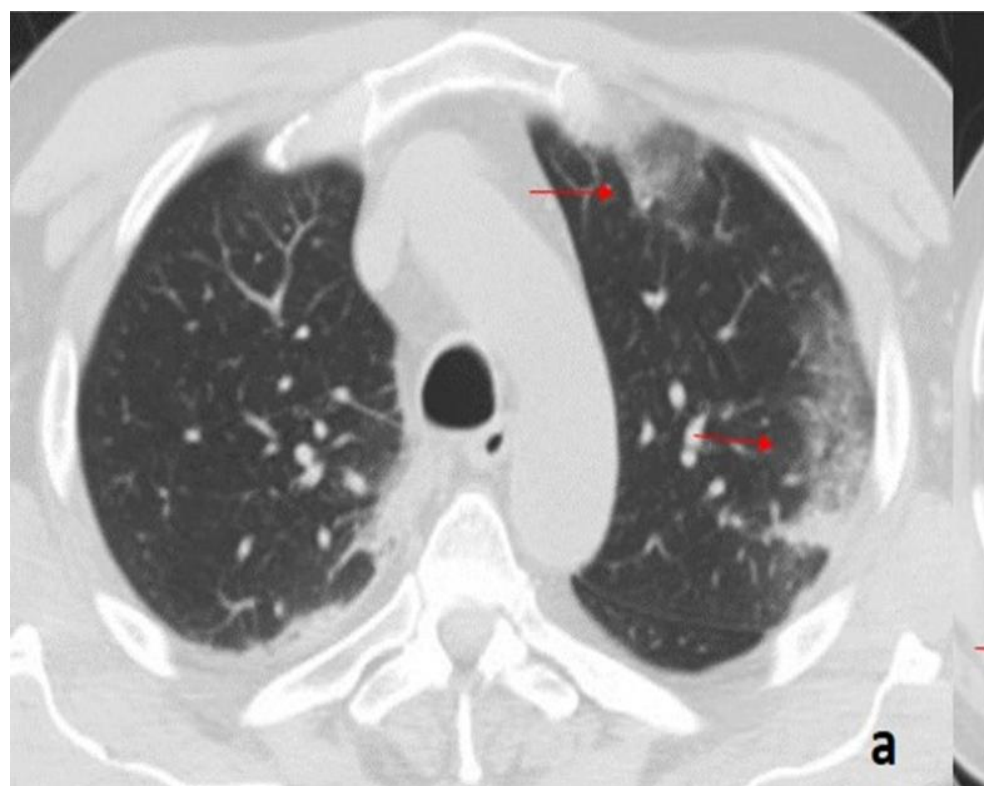

Figure 5: 66-year-old man with COVID-19 pneumonia.

FINDINGS: Axial unenhanced chest CT shows bilateral patchy GGOs superimposed on septal thickening (crazy paving pattern) with a pronounced peripheral distribution (arrows in a) and partial consolidation of the right lower lobe (arrows in b).

TECHNIQUE: GE 16-slices CT scanner, 80-300 mAs, $120 \mathrm{kV}, 1.25 \mathrm{~mm}$ slice thickness. 


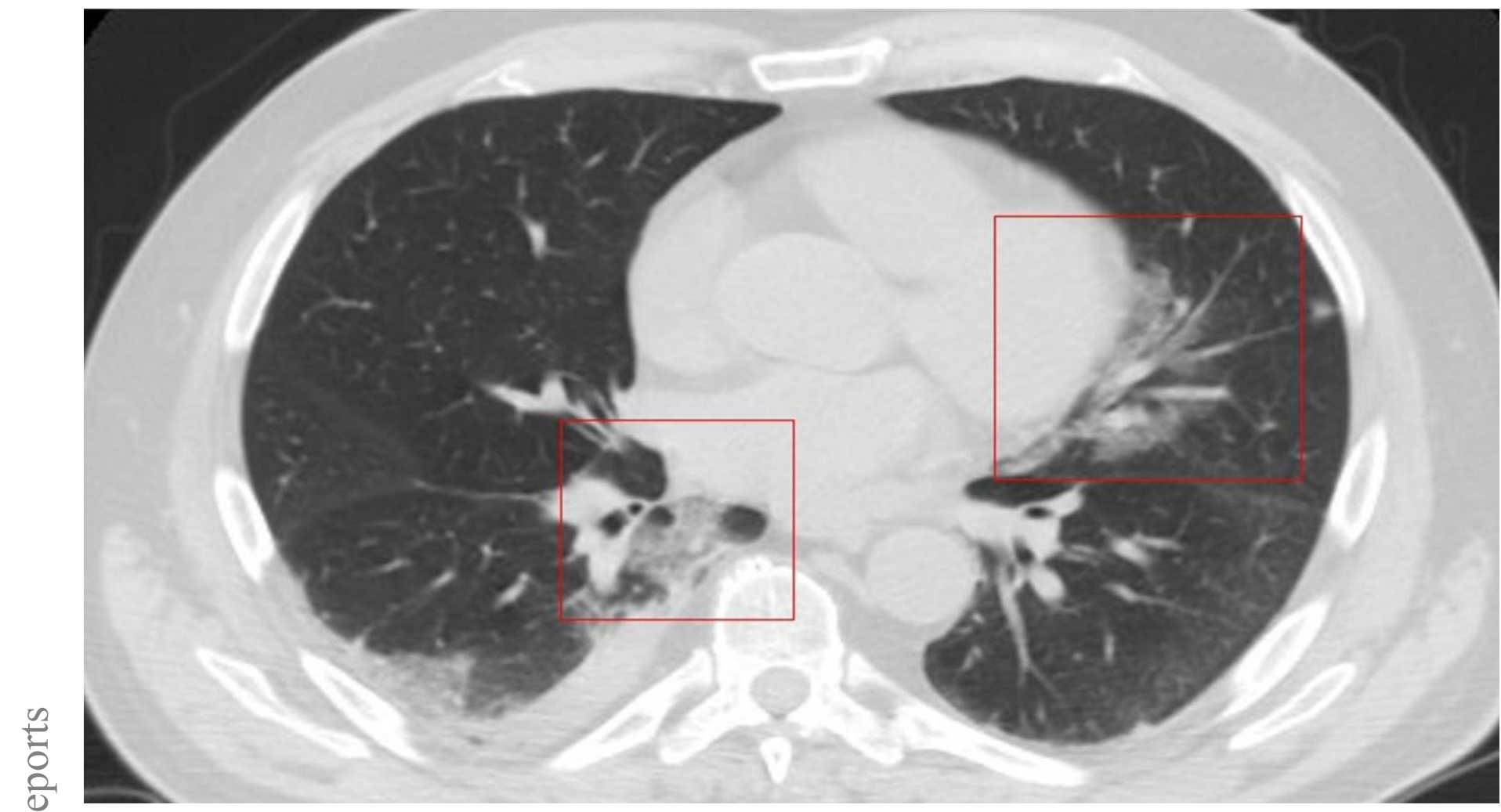

Figure 6: 66-year-old man with COVID-19 pneumonia.

FINDINGS: Axial unenhanced chest CT shows a right pleural effusion and patchy GGOs in the mediastinal subpleural areas (left paracardiac parenchyma and right posterior costo-mediastinal area (boxes)).

TECHNIQUE: GE 16-slices CT scanner, 80-300 mAs, $120 \mathrm{kV}, 1.25 \mathrm{~mm}$ slice thickness.
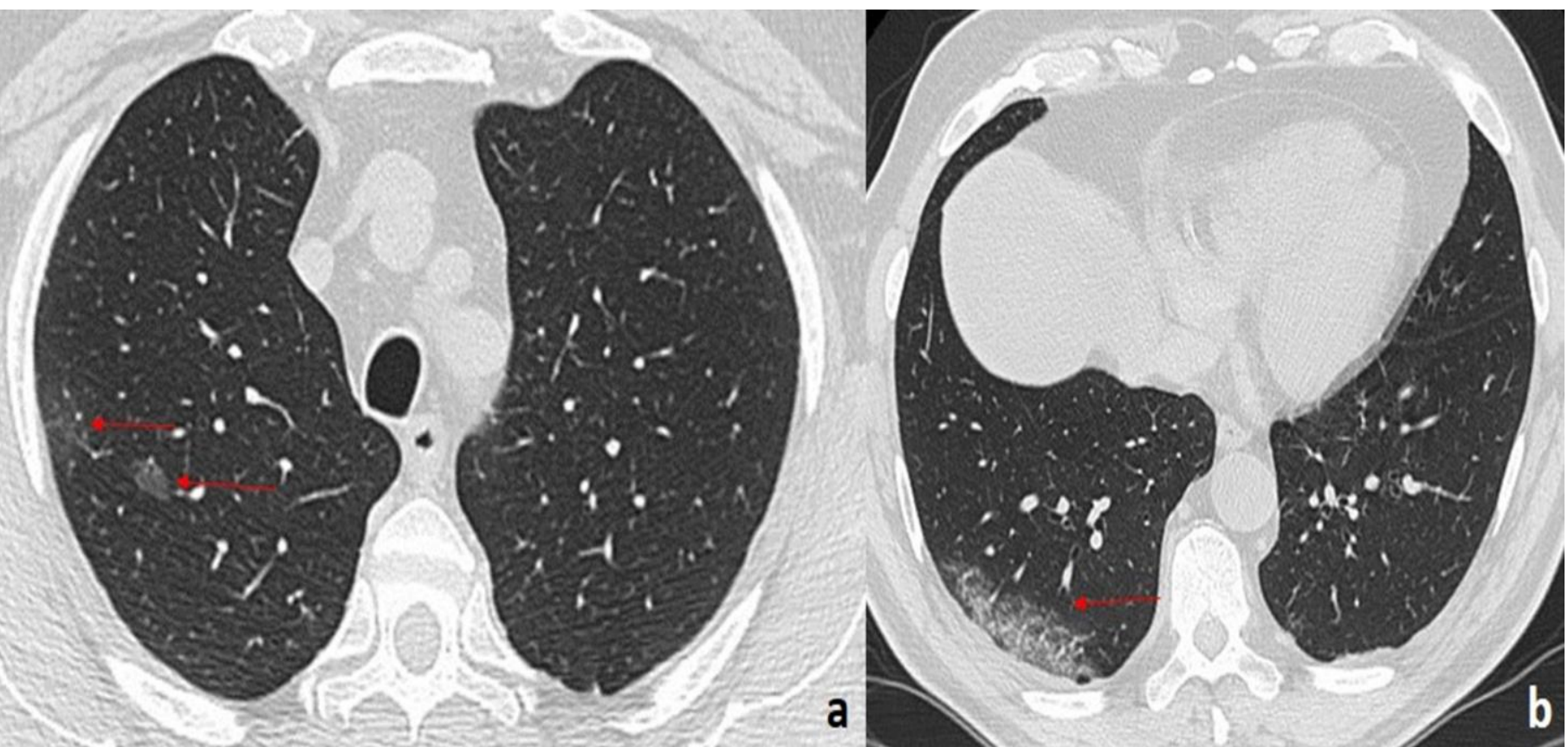

Figure 7: 61-year-old man with COVID-19 pneumonia.

FINDINGS: Axial unenhanced CT shows multiple rounded GGOs in the right upper lobe (arrows in a) and a diffuse GGO with contextual septal thickening (crazy paving pattern) in the periphery of the right lower lobe (arrow in b).

TECHNIQUE: GE 16-slices CT scanner, 80-300 mAs, $120 \mathrm{kV}, 1.25 \mathrm{~mm}$ slice thickness. 


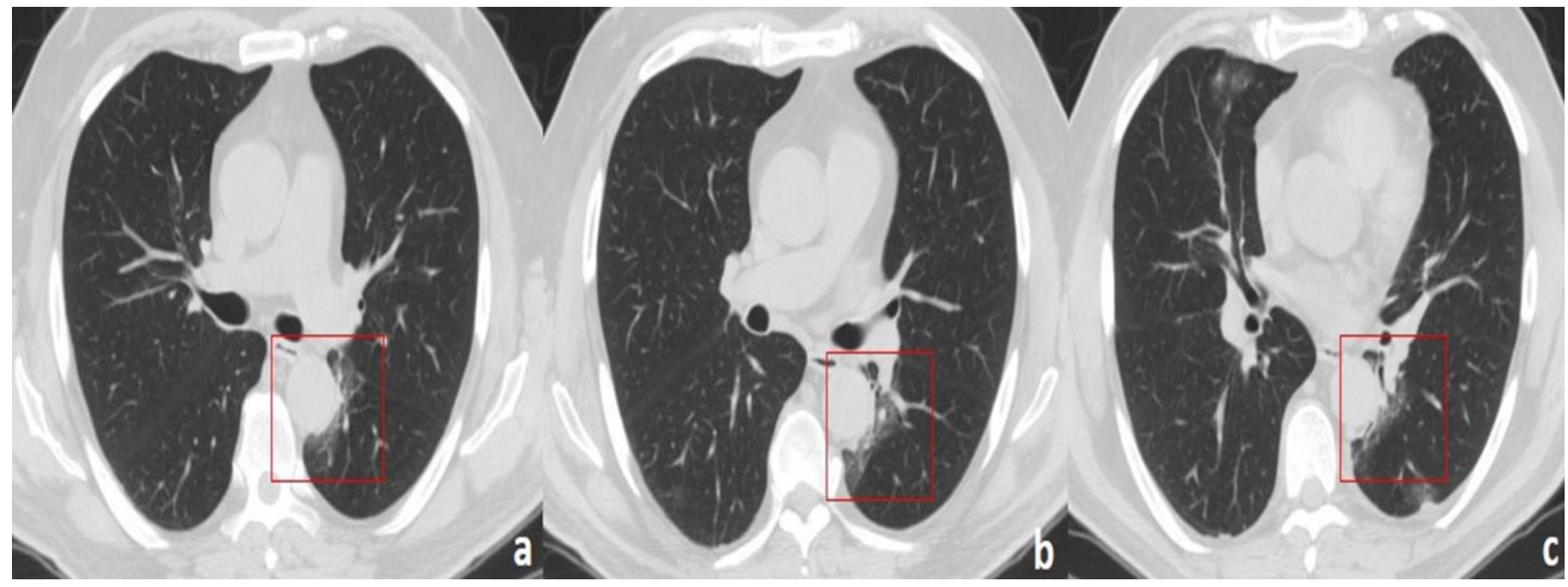

Figure 8: 61-year-old man with COVID-19 pneumonia.

FINDINGS: (a, b, c) Axial unenhanced CT shows area of band-like GGO around the thoracic descending aorta (boxes).

TECHNIQUE: GE 16-slices CT scanner, 80-300 mAs, $120 \mathrm{kV}, 1.25 \mathrm{~mm}$ slice thickness.

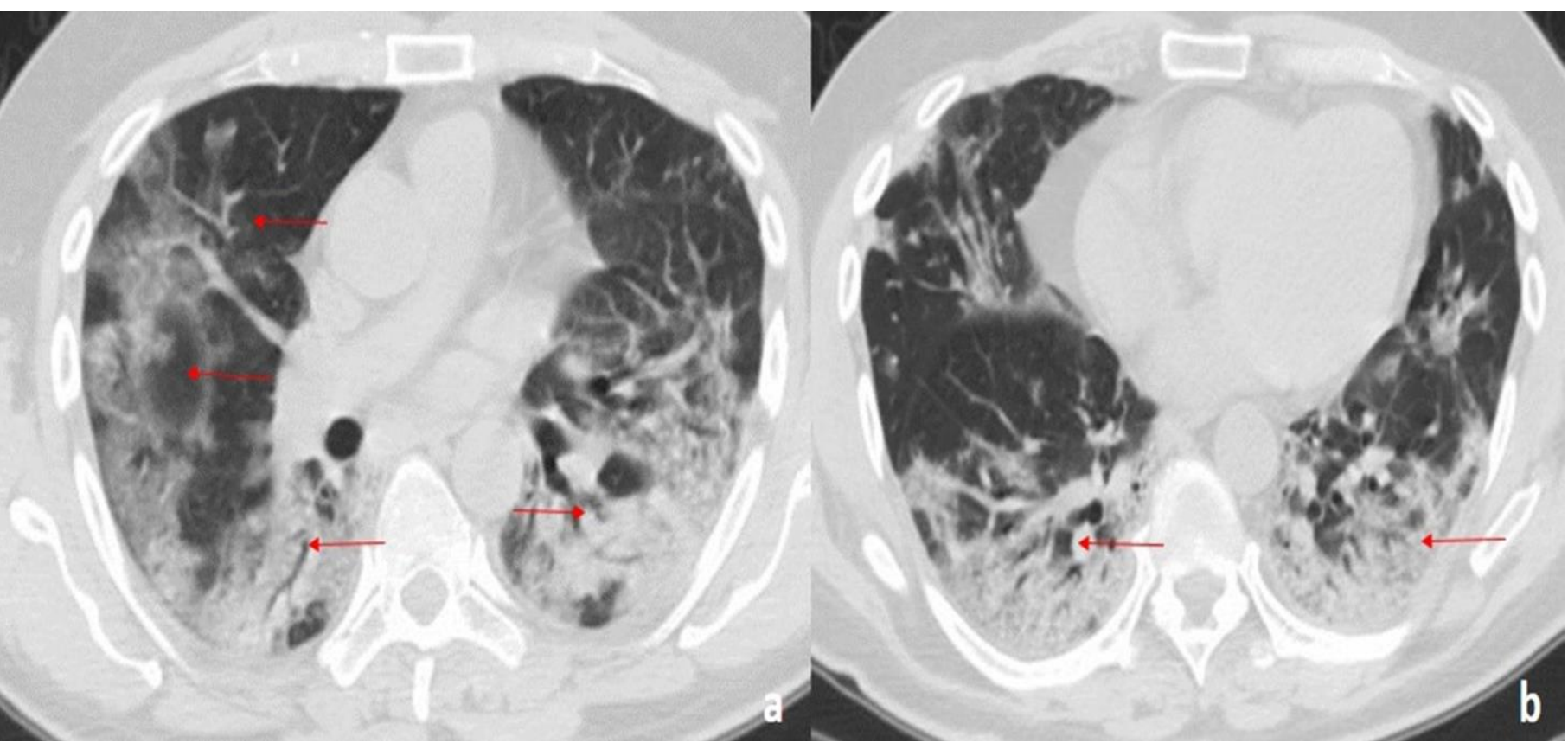

Figure 9: 58-year-old man with COVID-19 pneumonia.

FINDINGS: (a, b) Axial unenhanced CT demonstrates bilateral, diffuse GGOs with a bronchovascular and peripheral distribution. In the posterior segments of the lower lobes, consolidations with air bronchogram are also seen (arrows).

TECHNIQUE: GE 16-slices CT scanner, 80-300 mAs, $120 \mathrm{kV}, 1.25 \mathrm{~mm}$ slice thickness. 


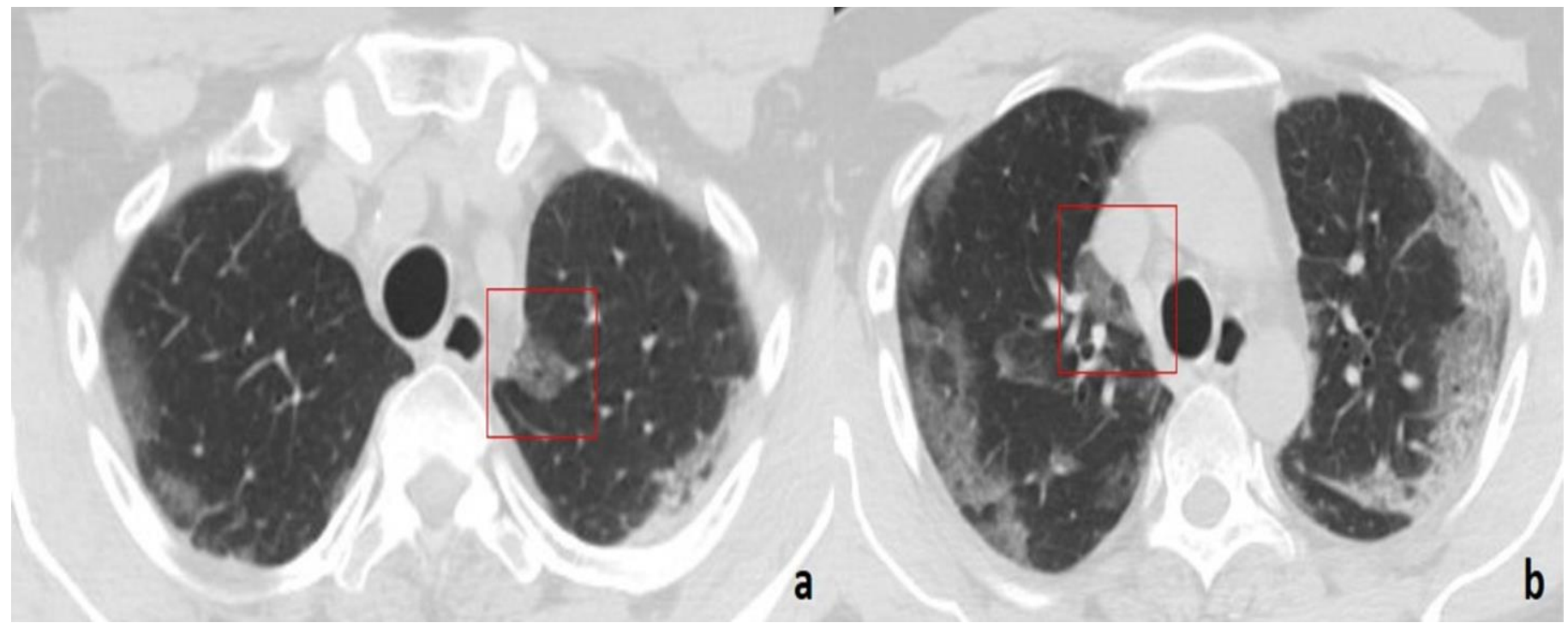

Figure 10: 58-year-old man with COVID-19 pneumonia.

FINDINGS: $(\mathrm{a}, \mathrm{b})$ Axial unenhanced CT shows focal rounded GGOs with a mediastinal subpleural distribution (paratracheal area bilaterally (boxes)).

TECHNIQUE: GE 16-slices CT scanner, 80-300 mAs, $120 \mathrm{kV}, 1.25 \mathrm{~mm}$ slice thickness.

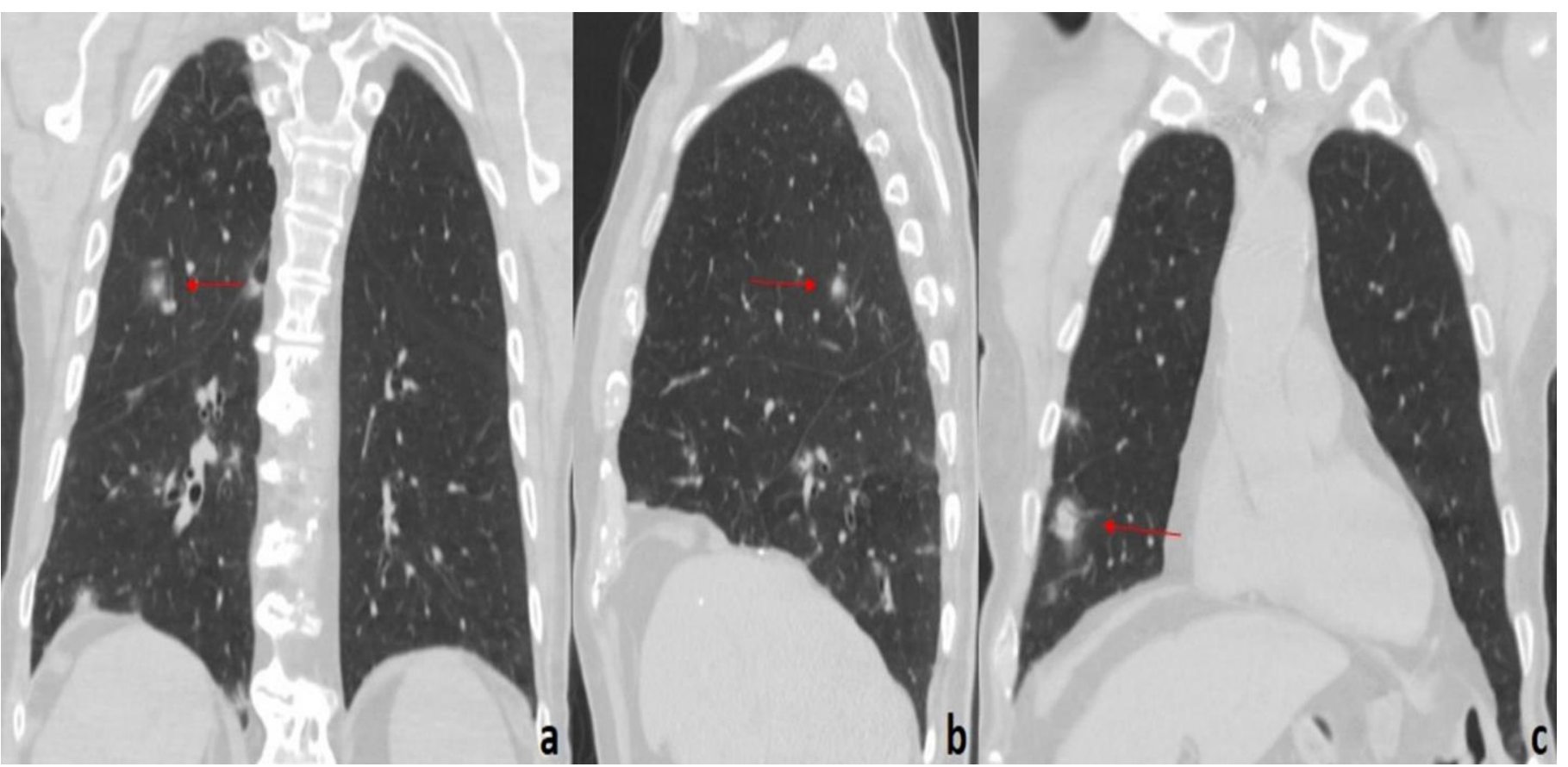

Figure 11: 75-year-old man with COVID-19 pneumonia.

FINDINGS: Coronal $(\mathrm{a}, \mathrm{c})$ and sagittal $(\mathrm{b})$ unenhanced CT of the chest demonstrates multiple nodules with faint surrounding ground glass attenuation (halo sign) in the right upper lobe (arrows in a, b) and right lower lobe (arrow in c).

TECHNIQUE: GE 16-slices CT scanner, 80-300 mAs, $120 \mathrm{kV}, 1.25 \mathrm{~mm}$ slice thickness. 


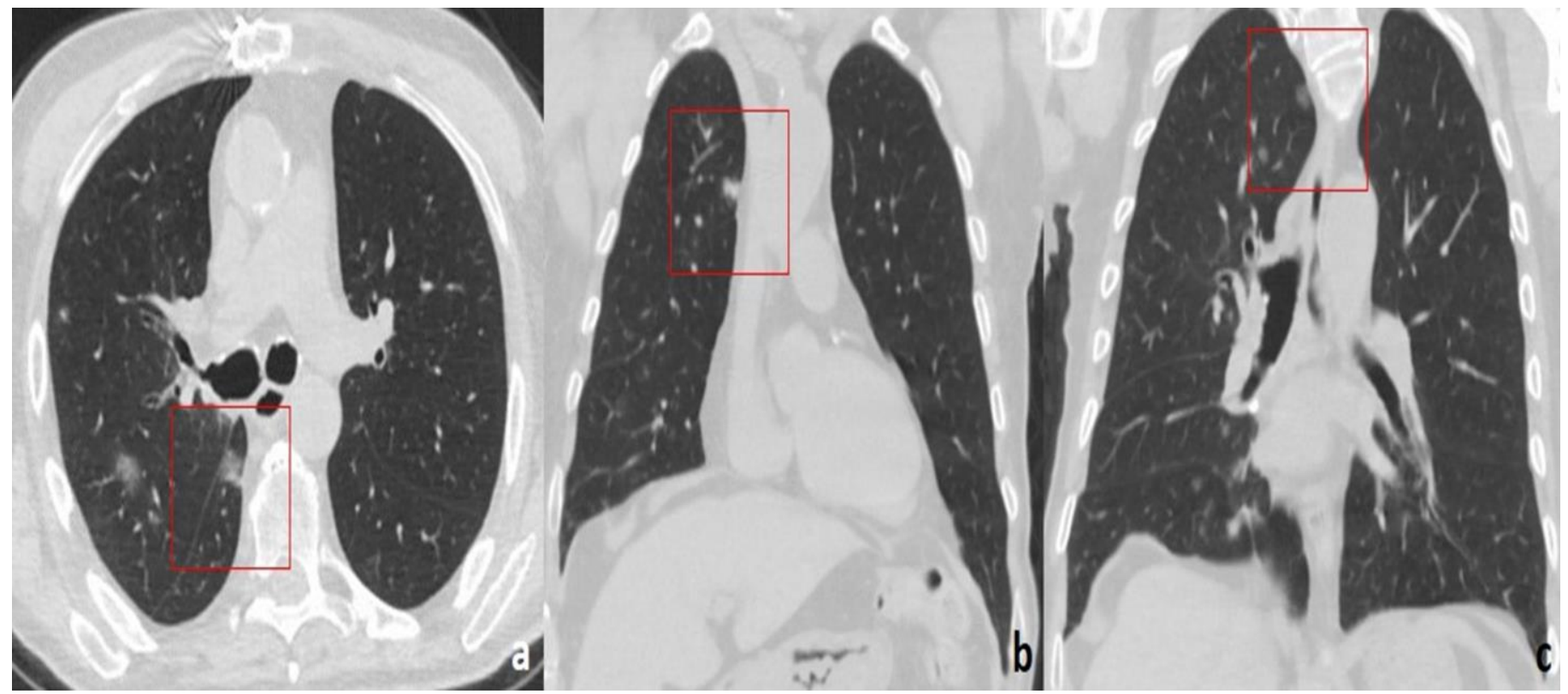

Figure 12: 75-year-old man with COVID-19 pneumonia.

FINDINGS: Axial (a)/coronal (b, c) unenhanced CT shows focal rounded GGOs in the mediastinal subpleural areas (right posterior costo-mediastinal area (box in a), right para-aortic area (box in b), and right paratracheal area (box in c)).

TECHNIQUE: GE 16-slices CT scanner, 80-300 mAs, $120 \mathrm{kV}, 1.25 \mathrm{~mm}$ slice thickness.

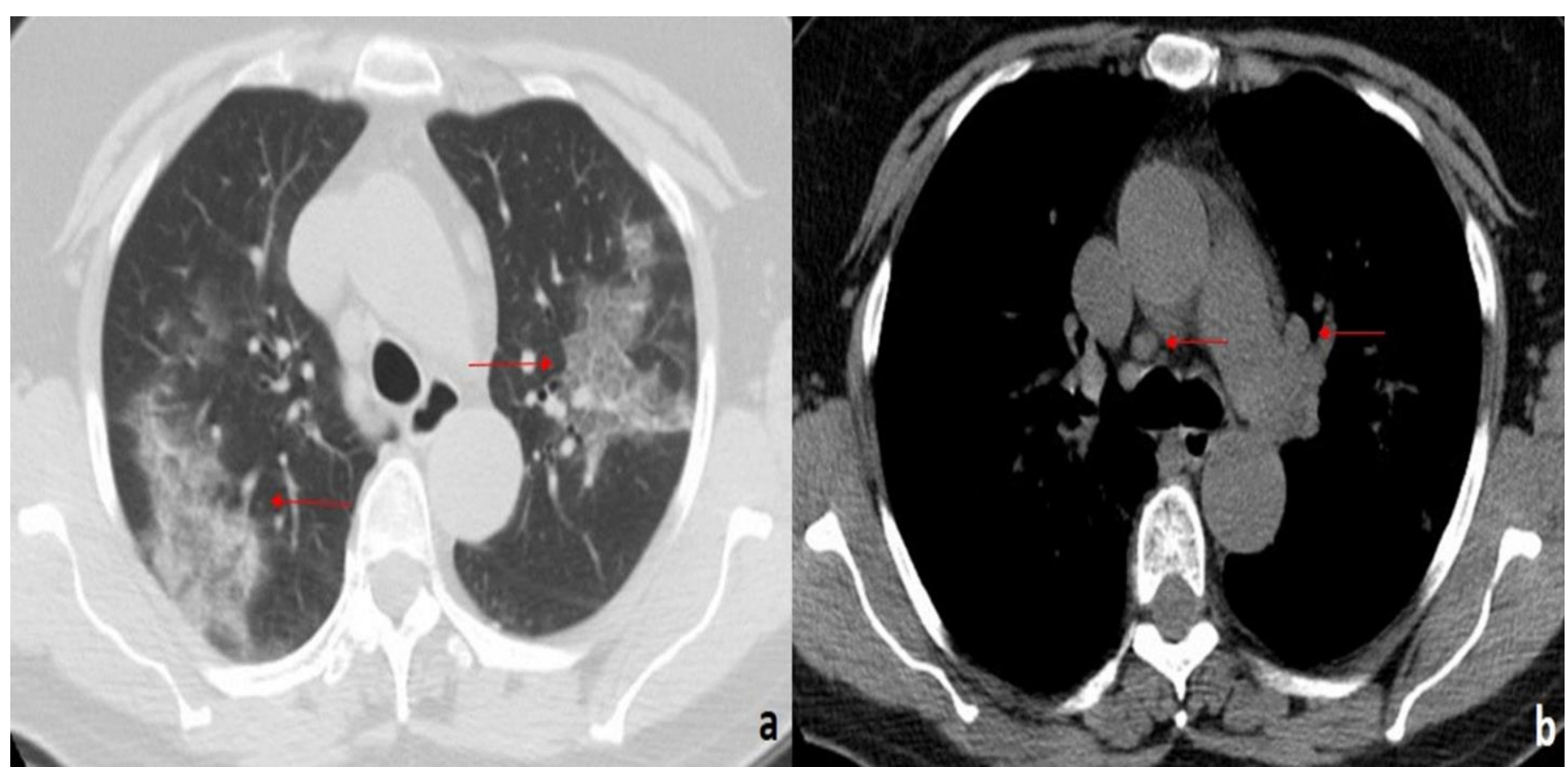

Figure 13: 60-year-old woman with COVID-19 pneumonia.

FINDINGS: Axial unenhanced chest CT shows bilateral, peripheral patchy areas of GGO with superimposed septal thickening (crazy paving pattern) in the upper lobes (arrows in a); evidence of enlargement of some mediastinal lymph nodes (arrows in b).

TECHNIQUE: GE 16-slices CT scanner, 80-300 mAs, $120 \mathrm{kV}, 1.25 \mathrm{~mm}$ slice thickness. 


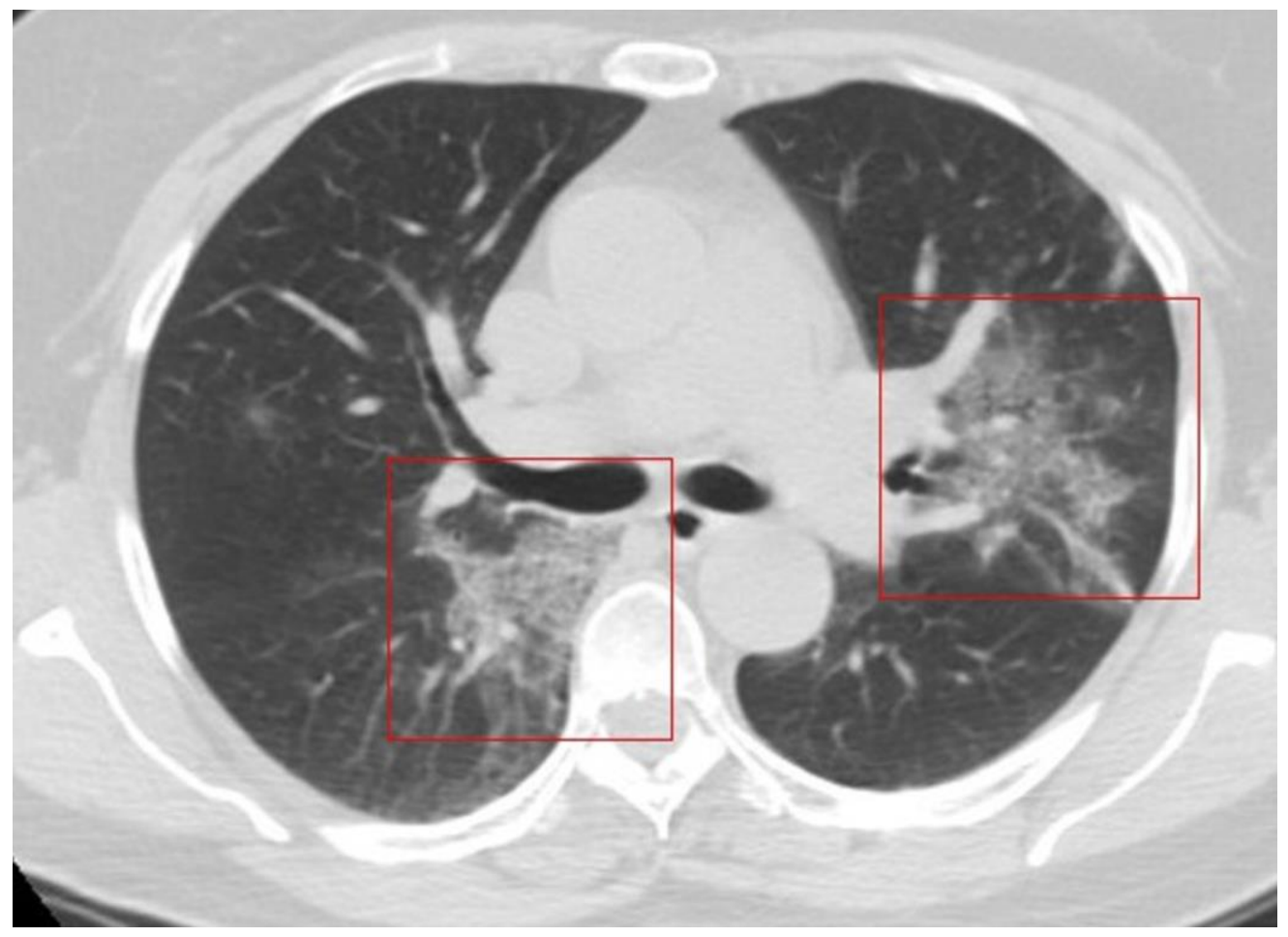

Figure 14: 60-year-old woman with COVID-19 pneumonia.

FINDNGS: Axial unenhanced chest CT shows areas of GGO with contextual septal thickening (crazy paving pattern) in a mediastinal subpleural distribution (right costo-mediastinal space) and in the left perihilar space (boxes).

TECHNIQUE: GE 16-slices CT scanner, 80-300 mAs, $120 \mathrm{kV}, 1.25 \mathrm{~mm}$ slice thickness

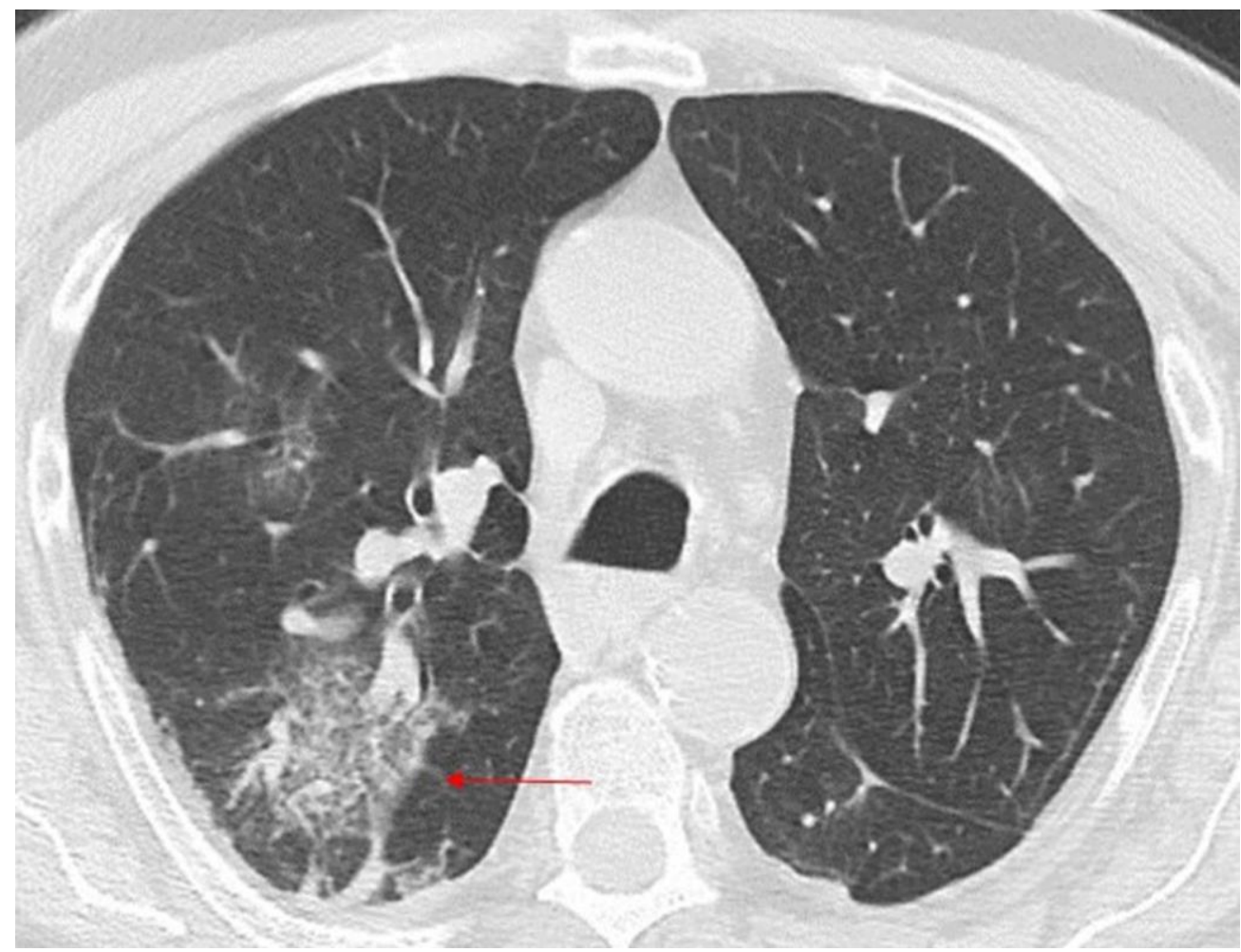

Figure 15: 86-year-old man with COVID-19 pneumonia.

FINDINGS: Axial unenhanced chest CT shows patchy GGO in the apical segment of the right lower lobe (arrow).

TECHNIQUE: GE 16-slices CT scanner, 80-300 mAs, $120 \mathrm{kV}, 1.25 \mathrm{~mm}$ slice thickness. 


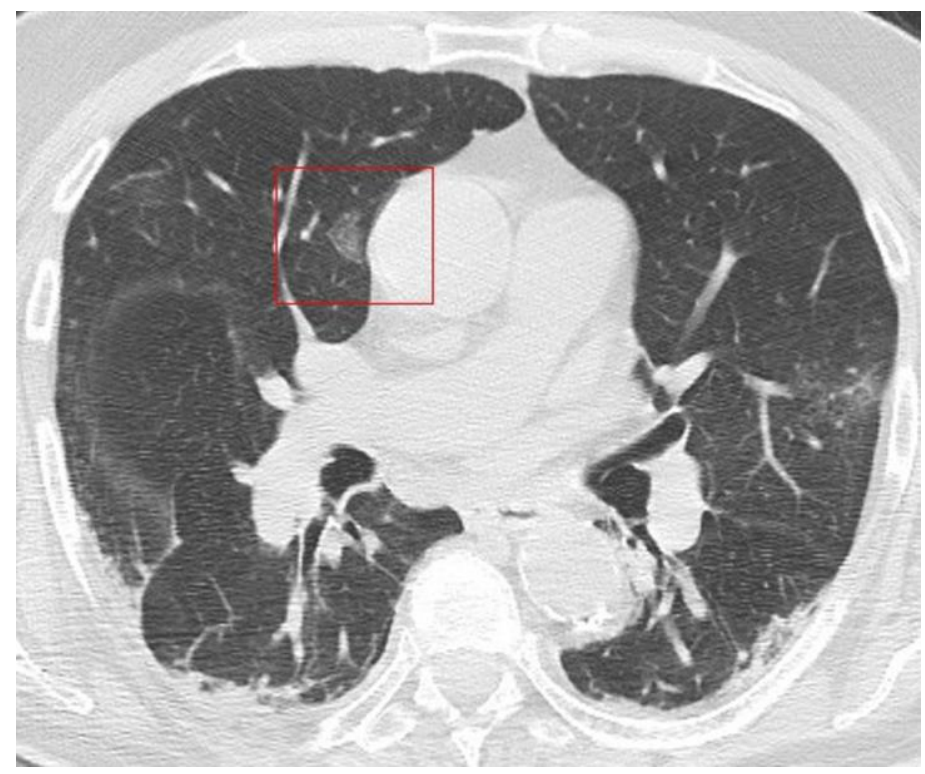

Figure 16 (left): 86-year-old man with COVID-19 pneumonia.

FINDINGS: Axial unenhanced chest CT shows a focal GGO with a mediastinal subpleural distribution in the right periaortic area (box).

TECHNIQUE: GE 16-slices CT scanner, 80-300 mAs, 120 $\mathrm{kV}, 1.25 \mathrm{~mm}$ slice thickness.

\begin{tabular}{|c|c|}
\hline Etiology & $\begin{array}{l}\text { Infectious disease caused by severe acute respiratory syndrome coronavirus } 2 \text { (SARS-CoV-2), previously } \\
\text { known as the } 2019 \text { novel coronavirus }(2019-\mathrm{nCoV}) \text {, a strain of coronavirus }\end{array}$ \\
\hline Incidence & As of October 27, 2020, a total of 43,341,451 cases and 1,157,509 deaths in over 200 countries \\
\hline Gender ratio & Males > females \\
\hline $\begin{array}{l}\text { Median age } \\
\text { predilection }\end{array}$ & $47-59$ \\
\hline Risk factors & $\begin{array}{l}\text { Most common comorbidities (observed in deceased patients in Italy) } \\
\text { - Hypertension } \\
\text { - Diabetes } \\
\text { - Ischemic heart disease } \\
\text { - Atrial fibrillation } \\
\text { - Chronic renal failure } \\
\text { - Active cancer in past five years } \\
\text { - Dementia } \\
\text { - Stroke } \\
\text { - Chronic liver disease }\end{array}$ \\
\hline Treatment & $\begin{array}{l}\text { In Italy, antibiotics were used in } 84 \% \text { of patients during the hospital stay, while antivirals }(54 \%) \text { and } \\
\text { corticosteroids }(31 \%) \text { were less commonly used. Concomitant use of these treatments was observed in } \\
18.6 \% \text { of cases }\end{array}$ \\
\hline Prognosis & 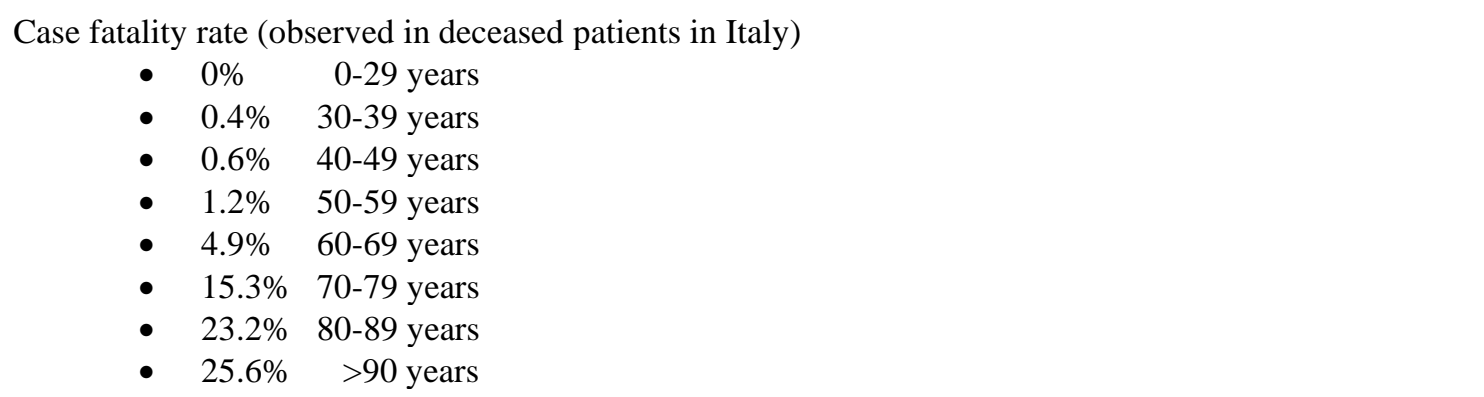 \\
\hline $\begin{array}{l}\text { Imaging } \\
\text { Findings }\end{array}$ & Multifocal bilateral ground glass opacities, typically with a peripheral and subpleural distribution \\
\hline
\end{tabular}

Table 1: Summary table for Coronavirus disease 2019 (COVID-19). 


\begin{tabular}{|c|c|c|}
\hline & CT & X-ray \\
\hline COVID-19 & $\begin{array}{l}\text { - Multifocal bilateral patchy ground glass opacities with a } \\
\text { subpleural distribution } \\
\text { - Crazy-paving pattern: ground glass opacities with } \\
\text { superimposed reticular and/or interlobular septal thickening } \\
\text { - Pure consolidation } \\
\text { - Reverse halo sign: a rounded area of ground glass surrounded } \\
\text { by a complete or almost complete ring of consolidation }\end{array}$ & $\begin{array}{l}\text { - Airspace opacities (consolidations or } \\
\text { ground glass opacities) with bilateral and } \\
\text { peripheral distribution } \\
\text { - Pleural effusion }\end{array}$ \\
\hline $\begin{array}{l}\text { Influenza A } \\
\text { (H1N1) }\end{array}$ & $\begin{array}{l}\text { - Combination of small patchy ground glass and consolidative } \\
\text { opacities with a subpleural and/or peribronchial distribution }\end{array}$ & $\begin{array}{l}\text { - Central or peripheral ground glass } \\
\text { opacities and consolidations }\end{array}$ \\
\hline SARS & $\begin{array}{l}\text { - Subpleural ground glass opacities (unilateral or bilateral) } \\
\text { associated with consolidation, particularly in the lower lobe } \\
\text { - Interlobular and intralobular septal thickening }\end{array}$ & $\begin{array}{l}\text { - Focal opacities } \\
\text { - Multifocal opacities in the middle and } \\
\text { lower zones } \\
\text { - Ground-glass opacities (unilateral or } \\
\text { bilateral) }\end{array}$ \\
\hline MERS & $\begin{array}{l}\text { - Extensive bilateral subpleural ground glass opacities } \\
\text { - Interlobular and intralobular septal thickening } \\
\text { - Pleural effusions }\end{array}$ & $\begin{array}{l}\text { - Peripheral ground glass opacities and } \\
\text { consolidations } \\
\text { - Pneumothorax } \\
\text { - Pleural effusions }\end{array}$ \\
\hline
\end{tabular}

Table 2: Differential diagnosis table for Coronavirus disease 2019 (COVID-19).

\section{ABBREVIATIONS}

ALC $=$ Absolute lymphocyte count

$\mathrm{CMV}=$ Cytomegalovirus

COVID-19 = Coronavirus disease 2019

$\mathrm{CRP}=\mathrm{C}$-reactive protein

$\mathrm{CT}=$ Computed tomography

GGO = Ground glass opacity

HRCT $=$ High-resolution computed tomography

LDH = Lactic dehydrogenase

MERS = Middle east respiratory syndrome

MPR = Multiplanar reformation

$\mathrm{PCT}=$ Procalcitonin

RT-PCR $=$ Real-time reverse transcription polymerase chain reaction

SARS $=$ Severe acute respiratory syndrome

SARS-CoV-2 = Severe acute respiratory syndrome coronavirus

$\mathrm{sO} 2=$ Oxygen saturation

$\mathrm{WBC}=$ White blood cell count

\author{
Online access \\ This publication is online available at: \\ www.radiologycases.com/index.php/radiologycases/article/view/3974
}

\section{Peer discussion}

Discuss this manuscript in our protected discussion forum at: www.radiolopolis.com/forums/JRCR

\section{Interactivity}

This publication is available as an interactive article with scroll, window/level, magnify and more features. Available online at www.RadiologyCases.com

Published by EduRad

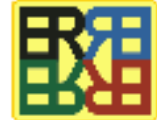

www.EduRad.org

\section{KEYWORDS}

Coronavirus disease 2019; COVID-19; chest CT; ground-glass opacities; GGOs; lung consolidation; mediastinal pleura 